\section{Use of Coated Tubing as Columns for Gas Chromatography}

THE original suggestion by Martin ${ }^{1}$ for the use of columns $0.2 \mathrm{~mm}$. in diameter in gas chromatography has been put to use with considerable success. The first theoretical and practical considerations of coated tubular columns were recently described by Burrows ${ }^{2}$ and Golay ${ }^{2}$. Later, with the advent of ionization detectors, the usefulness of such micro columns was extended ${ }^{3}$.

Columns made of nylon tubing for use in gas chromatography have been studied by Scott ${ }^{4}$. High efficiencies were obtained with columns of 0.01 in. and 0.02 in. in diameter. With larger diameter coated columns the efficiency decreased considerably.

One of the major obstacles to the use of coated capillary columns for research has been the small sample sizes required, particularly where it is desirable to trap fractions for further analysis. Whereas conventional detectors and columns use milligram loads, capillary columns of 0.01 in. diameter demand rgm. loads. The low cost and availability of nylon tubing in varying diameters has prompted a study of the effect of sample load with the diameter of coated tubular columns.

Columns of 0.02 in., and 0.034 in. diameter were used in $1,000 \mathrm{ft}$. lengths. These were coated by slowly passing a 10 per cent $\mathrm{w} / \mathrm{v}$ solution of the substrate in methylene chloride or pentane. Samples were introduced by means of a syringe directly into the column. A $0 \cdot 02$-in. diameter nylon column was able to support a sample load of I $\mathrm{mgm}$. without adversely affecting the shapes of the peaks. Efficiencies up to 250,000 plates were obtained on hydrocarbon samples. The 0.034 in. column was successfully used with 2-mgm. sample loads. Squalane, hexadecane, and isoquinoline were used as liquid substrates and the samples analysed were $\mathrm{C}_{2}-\mathrm{C}_{2}$ paraffins and naphthenes.

A nylon column 1 mile in length and having an inside diameter of $0.066 \mathrm{in}$. was coated in $1,000 \mathrm{ft}$. lengths with hexadecane. This column accepted samples up to $20 \mathrm{mgm}$. and gave efficiencies in excess of a million theoretical plates. Gas flow-rates of $250 \mathrm{ml}$. per min. were used in order to effect analyses in less than $2 \mathrm{hr}$. It appears then, that sample loads for coated tubular nylon columns are proportional to the available surface area or the amount of coating for the whole column. If an argon ionization detector is used the sample can be split prior to entering the cell $^{5}$. For the analyses of trace constituents a bypassing device may be arranged whereby the major components would be split at the end of the column and all the minor constituents would go directly into the cell.

Department of Chemistry,

Albert Zlatikis

H. R. KaUfMaN

University of Houston,

Houston, Texas.

Nov. 4.

'Martin, A.J. P., in 'Vapour thase Chromatography', 2, ed. by Desty, D. H. (1957).

Burrows, G., Trans. Inst. Chem. Eng., 35, 245 (1957). Golay, M. J. E., in 'Gas Chromatography', 1, ed. by Coates, Noebols and Fagerson (1957) : in 'Vapour Phase Chromatography', 36, ed. by Desty,

Desty, D. H., Nature, 183, 107 (1959). Desty, D. H., J. Instit. Pet. 45, $287(1959)$. Zlatkis, A., and Lovelock, J. E., Anal. Chem., 31, 620 (1959). Lipsky, S. R, and Lovelock, J. H., Anal. Chen

4 Scott, R. P. W. Nature, 184'(1959).

s Lantz, C. D., and Johnson, R. E., Gulf Coast Spectroscopic Group Meeting, Houston, Texas (October 2, 1959).

\section{Analysis of Light Hydrocarbons}

A RECENT communication by Barnard and Hughes ${ }^{1}$ described the gas chromatographic separation of ethane, ethylene, propane and propylene. Two column packings were used, triisobutylene on 'Celite' and ethylene glycol saturated with silver nitrate on 'Celite'. It was claimed that the four gases were separated on a column packed with a mixture of the two packings, whereas the same proportions arranged in two separate columns in series did not effect the same separation. As the two liquids are immiscible, the reported result is not in accordance with expectation ; a series of experiments have been carried out to check this conclusion.

${ }^{T}$ Two 4 -ft. columns were packed with tri isobutylene on 'Celite' and ethylene glycol containing silver nitrate on 'Celite' respectively. 'The retention volumes at $12^{\circ} \mathrm{C}$. of hydrogen, ethane, ethylene, propane and propylene were measured on these columns $(a)$ separately, $(b)$ in series (triisobutylene second) and again (c) after the columns had been unpacked, their contents mixed, and the columns repacked with the mixture. The experiment was repeated with one 4 -ft. and one 2 -ft. column packed with ethylene glycol/silver nitrate/'Celite' and one 2-ft. column packed with triisobutylene/'Celite'. Retention volumes with the columns $(a)$ in series and $(b)$ with their contents mixed were measured. As ethylene glycol is slightly hygroscopic and trissobutylene is volatile, a careful check was kept on changes in weight throughout.

Specific retention volumes for the hydrocarbon gases were calculated for each column or combination of columns. The actual retention volumes, from the hydrogen peak, were measured at the temperature and exit pressure of the column and corrected for the pressure drop across the column. The corrected volume was divided by the total weight of stationary phase (excluding support) in the column(s); the weight used was that calculated from a weighing

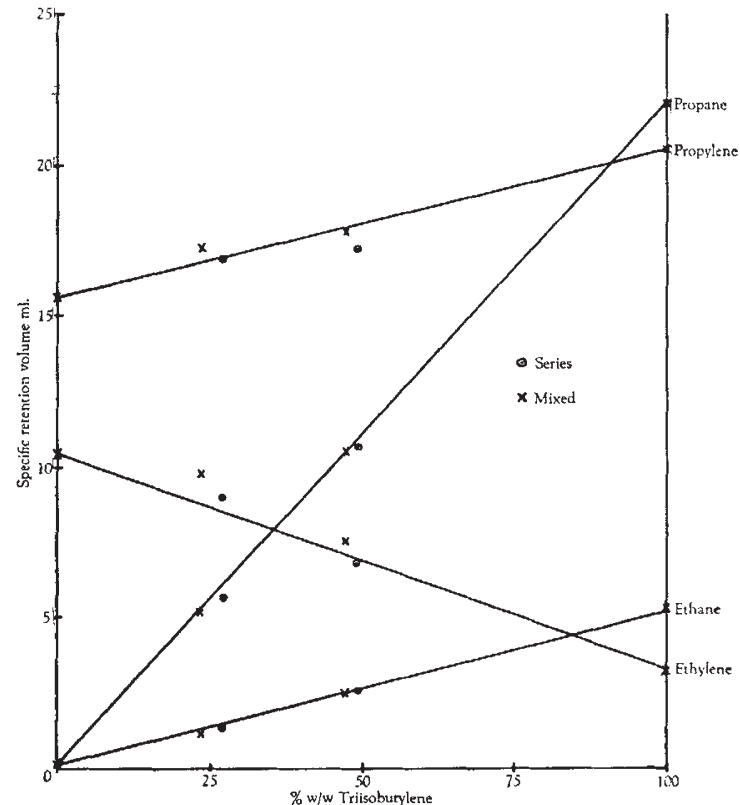

Fig. 1. Specific retention volume plotted against per cent $w / w$

tri-isobutylene in the mixture.
The scatter of the points about the straight tie-lines in Fig. 1 is within the experimental error of determination of the specific retention volumes, for these rather low values. The result indicate that there is no large difference in effect between separate columns in series and an equal number of columns with mixed 